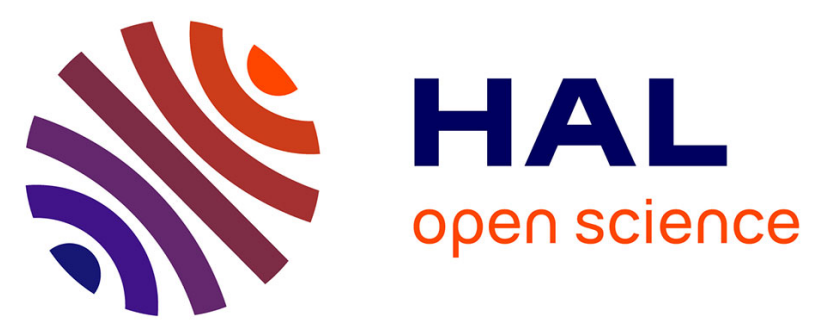

\title{
Nanoselective area growth of defect-free thick indium-rich InGaN nanostructures on sacrificial $\mathrm{ZnO}$ templates
}

Renaud Puybaret, David Rogers, Youssef El Gmili, Suresh Sundaram, Matthew B Jordan, Xin Li, Gilles Patriarche, Ferechteh Teherani, Eric Sandana, Philippe Bove, et al.

\section{To cite this version:}

Renaud Puybaret, David Rogers, Youssef El Gmili, Suresh Sundaram, Matthew B Jordan, et al.. Nanoselective area growth of defect-free thick indium-rich InGaN nanostructures on sacrificial $\mathrm{ZnO}$ templates. Nanotechnology, 2017, 28 (19), pp.195304. 10.1088/1361-6528/aa6a43 . hal-01830993

\section{HAL Id: hal-01830993 https://hal.science/hal-01830993}

Submitted on 24 Feb 2022

HAL is a multi-disciplinary open access archive for the deposit and dissemination of scientific research documents, whether they are published or not. The documents may come from teaching and research institutions in France or abroad, or from public or private research centers.
L'archive ouverte pluridisciplinaire HAL, est destinée au dépôt et à la diffusion de documents scientifiques de niveau recherche, publiés ou non, émanant des établissements d'enseignement et de recherche français ou étrangers, des laboratoires publics ou privés.

\section{(ㅇ)(1) $\$$}

Distributed under a Creative Commons Attribution - NonCommerciall 4.0 International 


\title{
Nanoselective area growth of defect-free thick indium-rich InGaN nanostructures on sacrificial $\mathrm{ZnO}$ templates.
}

\author{
Renaud Puybaret, ${ }^{1,2}$ David J. Rogers, ${ }^{3}$ Youssef El Gmili, ${ }^{2}$ Suresh Sundaram, ${ }^{2}$ Matthew B. Jordan, ${ }^{1,2}$ Xin Li, ${ }^{2}$ \\ Gilles Patriarche, ${ }^{4}$ Ferechteh H. Teherani, ${ }^{3}$ Eric V. Sandana, ${ }^{3}$ Philippe Bove, ${ }^{3}$ Paul L. Voss,,${ }^{1,2}$ Ryan McClintock, ${ }^{5}$ \\ Manijeh Razeghi, ${ }^{5}$ Ian Ferguson, ${ }^{6}$ Jean-Paul Salvestrini, ${ }^{7,2}$ and Abdallah Ougazzaden ${ }^{1,2, a)}$ \\ 1) Georgia Institute of Technology - School of Electrical and Computer Engineering - 30332 Atlanta GA - USA \\ ${ }^{2)}$ CNRS, GT UMI 2958, Georgia Tech Lorraine - 2 Rue Marconi 57070 Metz - France \\ ${ }^{3)}$ Nanovation, 8 Route de Chevreuse, 78117 Châteaufort, France \\ ${ }^{4)}$ CNRS, Laboratoire de Photonique et de Nanostructures - Route de Nozay 91460 Marcoussis - France \\ ${ }^{5)}$ Northwestern University, Center for Quantum Devices, Department of Electrical and Computer Engineering, \\ Evanston, IL60208 , USA \\ ${ }^{6)}$ Missouri University of Science and Technology - Department of Electrical and Computer Engineering - Rolla, \\ MO 65409 - USA \\ 7) Université de Lorraine $\&$ CentraleSupélec, LMOPS, EA4423, 57070 Metz, France
}

\begin{abstract}
Nanoselective area growth by metal organic vapor phase epitaxy of high-quality InGaN nanopyramids on GaN-coated $\mathrm{ZnO} / \mathrm{c}$-sapphire is reported. Nanopyramids grown on epitaxial low-temperature GaN-on-ZnO are uniform and appear to be single crystalline, as well as free of dislocations and V-pits. They are also indium-rich (with homogeneous $22 \%$ indium incorporation) and relatively thick (100 $\mathrm{nm}$ ). These properties make them comparable to nanostructures grown on GaN and $\mathrm{AlN} / \mathrm{Si}$ templates, in terms of crystallinity, quality, morphology, chemical composition and thickness. Moreover, the ability to selectively etch away the $\mathrm{ZnO}$ allows for the potential lift-off and transfer of the InGaN / GaN nanopyramids onto alternative substrates, e.g. cheaper and/or flexible. This technology offers an attractive alternative to NSAG on $\mathrm{AlN} / \mathrm{Si}$ as a platform for the fabrication of high quality, thick and indium-rich InGaN monocrystals suitable for cheap, flexible and tunable light-emitting diodes.
\end{abstract}

Keywords: InGaN, nano selective area growth (NSAG), metal organic vapour phase epitaxy (MOVPE)

The fundamental band gap of $\mathrm{GaN}$ can be tuned to cover the whole visible spectrum by alloying with indium $^{1}$. This capacity has already proven to be highly successful for the fabrication of light emitting diodes $(\mathrm{LEDs})^{2}$ and can potentially lead to the production of phosphor-free true white LEDs made of red, green and blue solid-state spontaneous emitters. However, the strong tendencies to compositional phase instability and relaxation of the layer due to lattice mismatches with conventional epitaxial substrates lead to indium clusters and large dislocation densities at the higher indium contents and film thicknesses necessary for absorption of the solar spectrum ${ }^{3-7}$. Hence the growth of highquality InGaN layers with over $15 \%$ of In incorporation and having suitable thickness remains challenging (even on GaN templates) $^{8,9}$. These issues are even more pronounced in the case of InGaN growth on silicon, as reported by several authors who recently grew InGaN layers (with up to $40 \%$ of indium content) on AlNbuffered Si (111) substrates by plasma-assisted molecular beam epitaxy (PA-MBE) and metal organic vapor phase epitaxy (MOVPE) $)^{10-13}$. Moreover these siliconbased processes may have additional disadvantages, like a longer processing time due to the back-etching of the Si substrate, and the resulting impossibility to re-use the

a) Electronic mail: aougazza@georgiatech-metz.fr wafer ${ }^{10-13}$. Thus it is desirable to develop novel approaches to improve the quality of thick and indiumrich InGaN epilayers. One potential solution is in the growth of InGaN nano-structures using a non-adsorbing masking material which could accommodate the elastic strain without the generation of dislocations ${ }^{14}$. Significant work has been reported on self-assembled InGaN nanostructures over the entire composition range using HVPE, but this process leads to a random distribution of island sizes ${ }^{15}$. Others have reported MBE growth of InGaN nanostructures on GaN-nanocolumn-buffered silicon substrates emitting from the ultraviolet $(3.2 \mathrm{eV})$ to the infrared $(0.78 \mathrm{eV})$ and achieved an internal quantum efficiency of $36 \%$ for green-emitting nanocolumns ${ }^{16}$. Using MOVPE, low indium content InGaN nanostructures have been selectively grown only on GaN templates by pulsing the precursors ${ }^{17}$. Recently, using continuous flow MOVPE on GaN templates and an improved patterning process, the growth of thick, uniform, dense, single phase, indium-rich nanorod arrays was demonstrated on both GaN/c-sapphire ${ }^{18,19}$ and AlN/Si wafers ${ }^{20}$. ZnO substrates offer a number of advantages over c-sapphire, $\mathrm{AlN} / \mathrm{Si}$ and wurtzite $\mathrm{SiC}$ wafers $^{21}$ : a lower lattice mismatch with $\mathrm{GaN}$ (1.8\% vs. resp. $16 \%$ and $4 \%$ ), a lattice match with $\operatorname{In}_{.22} \mathrm{Ga}_{78} \mathrm{~N}$, and a more similar c-axis thermal expansion coefficient ${ }^{22}$. Moreover, the compressive strain due to the growth on the $\mathrm{ZnO}$ underlayer promotes stabilisation of an InGaN compositional phase with enhanced indium content ${ }^{23,24}$. This approach also 


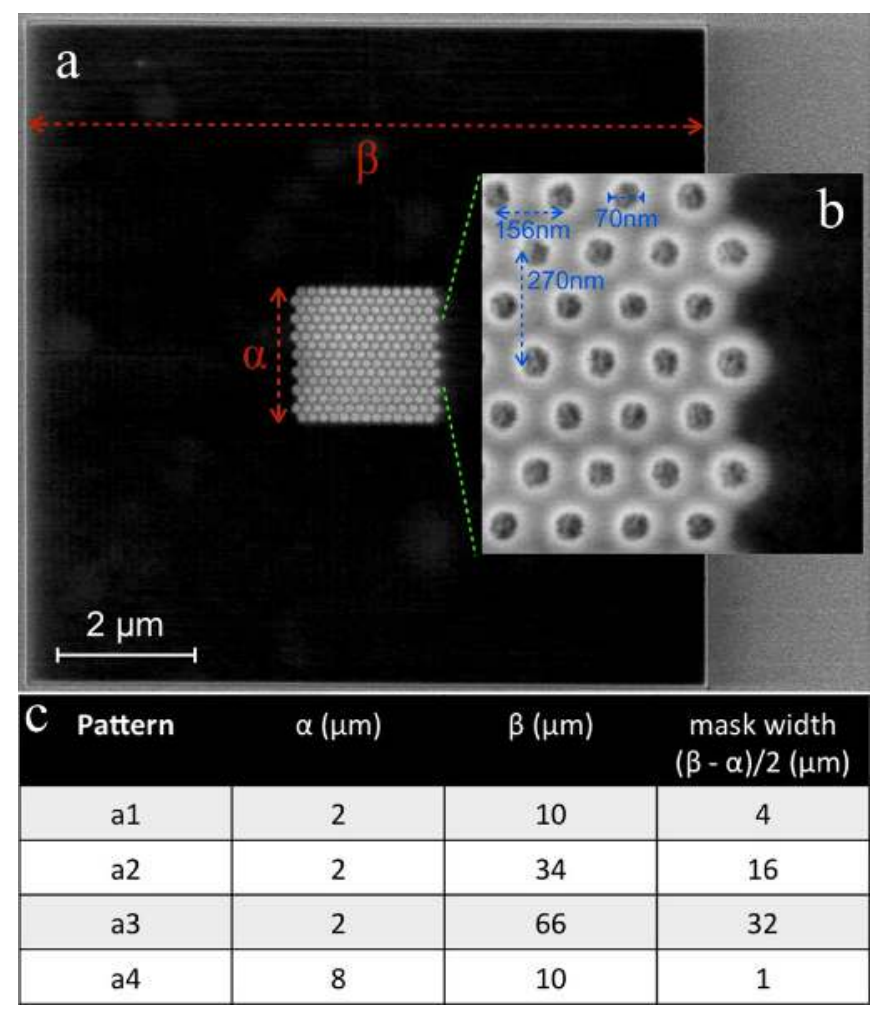

FIG. 1. Mask geometry. (a) Field-emission scanning electron microscope (SEM) image of a pattern of electron-beamexposed HSQ (dark on image) on a $\mathrm{GaN} / \mathrm{ZnO} / \mathrm{c}-\mathrm{Al}_{2} \mathrm{O}_{3}$ substrate. (b) SEM Zoom on the mask. (c) Definition of arrays (a1), (a2), (a3) and (a4) as a function of the variables $\alpha$ and $\beta$.

has the potential for transfer of nano InGaN-GaN structures onto alternative substrates (e.g. cheaper or flexible) through chemical liftoff via preferential etching of the $\mathrm{ZnO}$ underlayer ${ }^{25}$.

In this work, we demonstrate NSAG as a potential route which mitigates the technological blocks resulting in high quality InGaN nanostructures on $\mathrm{ZnO}$ templates. $\mathrm{ZnO}$ template layers were grown on c-sapphire using pulsed laser deposition (PLD) from a sintered $5 \mathrm{~N}$ $\mathrm{ZnO}$ target in a molecular oxygen ambient with a $248 \mathrm{~nm}$ KfF excimer laser ${ }^{26}$. Nanoselective area growth (NSAG) of InGaN was made by MOVPE through electron-beamexposed hydrogen silsesquioxane (HSQ) masks which were fabricated using a process described in Refs ${ }^{18,27}$. Several mask formats were used, as shown in Fig.1.

We first tried to pattern the HSQ directly on the $\mathrm{ZnO}$ without GaN on top, and then 100 nanometers of InGaN were grown. However it turned out that for MOVPE of InGaN above $730^{\circ} \mathrm{C} \mathrm{ZnO}$ starts decomposing ${ }^{28}$. Indeed at low growth temperature (around $730^{\circ} \mathrm{C}$ ), due to adsorption and lower migration of growth species on the surface of the $\mathrm{SiO}_{2}$, nucleation occurs on the exposed HSQ resulting in polycrystalline InGaN formation, leading to loss of selectivity, as seen in Fig.2. Furthermore both $\mathrm{NH}_{3}$ (the standard precursor gas for atomic nitrogen $\mathrm{N}$ ), and $\mathrm{H}_{2}$ (the standard carrier gas) back-etch the

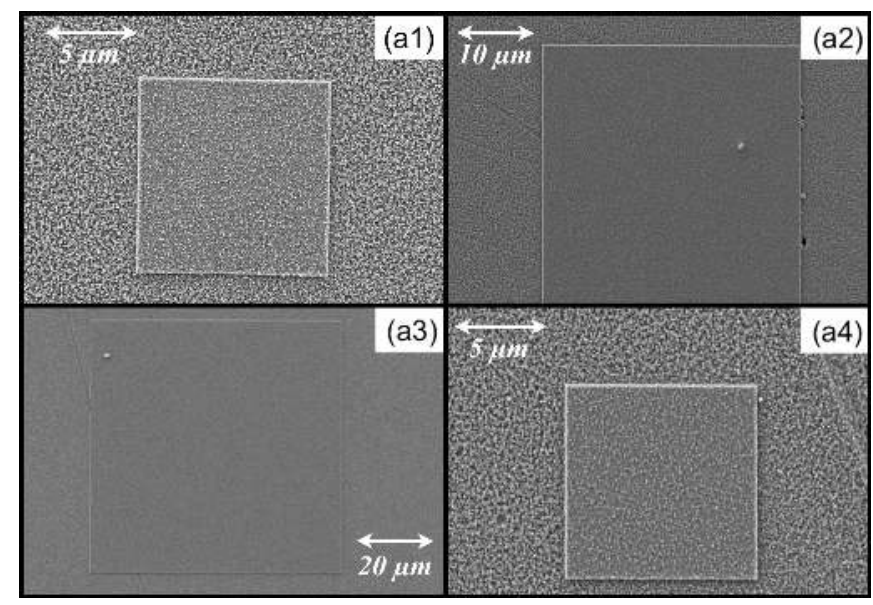

FIG. 2. SEM images of $100 \mathrm{~nm}$ of InGaN grown directly on patterned $\mathrm{ZnO}$ templates, showing motifs (a1) to (a4). As can be clearly observed, selectivity is lost, due to the relatively low temperature required for growth on the $\mathrm{ZnO}$ templates.
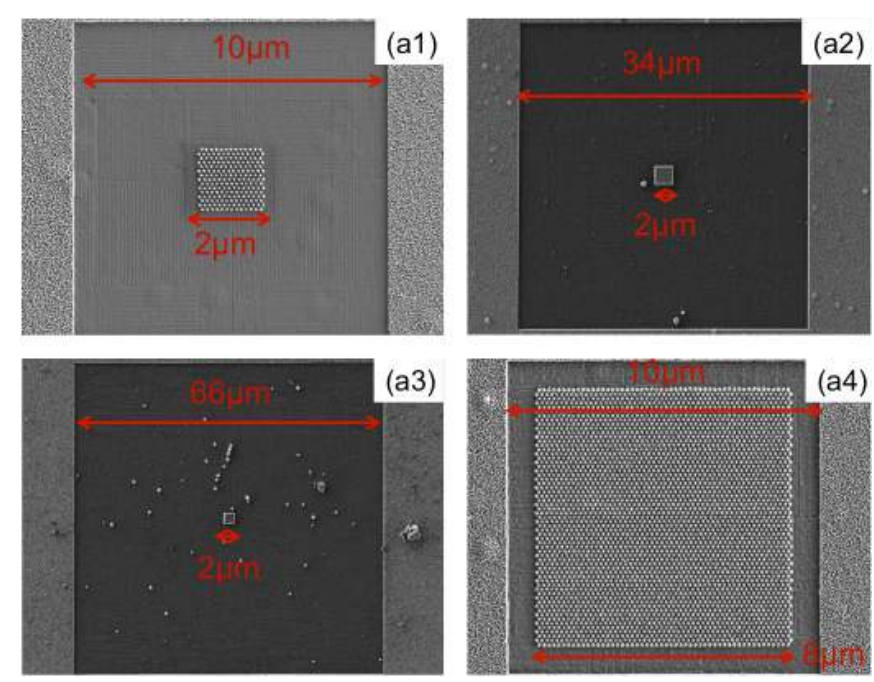

FIG. 3. SEM images of 100-nm-thick InGaN structures on a patterned $\mathrm{GaN}(100 \mathrm{~nm}) / \mathrm{ZnO}$ template, showing arrays (a1) to (a4). The protective MOVPE-grown 100-nm GaN coating allows growth at higher temperature $\left(800^{\circ} \mathrm{C}\right)$ without significant $\mathrm{ZnO}$ back-etching and thus restores selectivity.

surface of the $\mathrm{ZnO}$ at these temperatures, which can lead to delamination of the GaN layer ${ }^{29-31}$.

In previous work, the authors addressed the backetching of $\mathrm{ZnO}$ by growing high quality GaN by MOVPE under $\mathrm{N}_{2}$ carrier gas (normally $\mathrm{H}_{2}$ ) and replacing the ammonia with 1,1dimethylhydrazine (UDMH), cf Refs. ${ }^{32,33}$. The use of UDMH allows for a reduction of the GaN growth temperature from the conventional range of 1000$1100^{\circ} \mathrm{C}$ to a range of $550-800^{\circ} \mathrm{C}$ (henceforth referred to as low temperature, or LT).

Hence, in an attempt to restore selectivity, $100 \mathrm{~nm}$ of GaN were first grown epitaxially on the $\mathrm{ZnO}$ at LT and then an $\mathrm{SiO}_{2}$ overlayer mask was patterned using ebeam lithography on HSQ, cf Fig.1. SEM analysis shows that using this method InGaN growth at $800^{\circ} \mathrm{C}$ became 


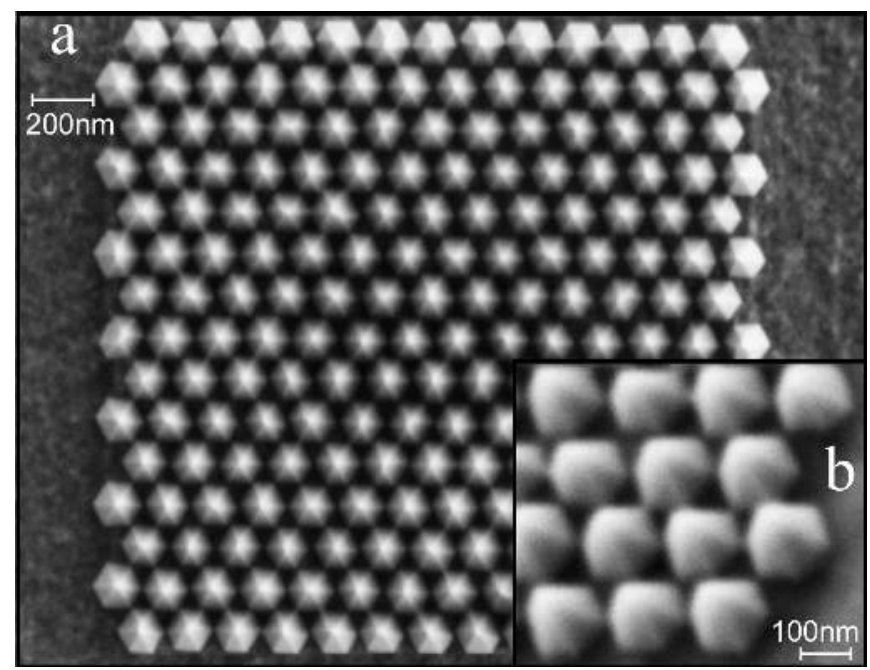

FIG. 4. SEM of pattern (a2), an array of 100-nanometer-thick In ${ }_{22} \mathrm{Ga} .{ }_{78} \mathrm{~N}$ defect-free wurtzite monocrystals. (a) Full array and (b) Zoom on the lower right corner at $37^{\circ}$ tilt angle.

perfectly selective on the $\mathrm{GaN} / \mathrm{ZnO} / \mathrm{Al}_{2} \mathrm{O}_{3}$ samples, as seen in Fig.3. Fig.4 shows that arrays of regularly-spaced InGaN nanopyramids have formed in the patterned areas. The nanopyramids exhibit aligned hexagonal faceting, and are homogenous in size, shape, and composition. The six smooth triangular semipolar (1101) facets indicate epitaxial growth. Each nanopyramid appears to be free from intrinsic defects within the detection limits of the SEM. The SEM images on Fig.4 do not show any V-pit (V-pits are usually the result of propagation of threading dislocations ${ }^{34,35}$ ). Whereas the planar InGaN in the unpatterened area exhibits 3D growth with $\mathrm{V}$-pits and other defects resulting in the rough morphological quality as vividly seen from the SEM image in Fig.3. As a remark we can notice evidence of micron-sized blisters in Figs.3(a1) and (a4) which may be due to the underlying $\mathrm{ZnO}$ starting to dissociate locally, but being blocked by the GaN. The main result here is the demonstration of a novel nano-patterning process that suits fragile $\mathrm{ZnO}$ templates, leading to the growth of InGaN nanopyramids on LT-GaN-covered $\mathrm{ZnO}$ templates with perfect selectivity.

Scanning transmission electron microscopy (STEM) images of the InGaN nanopyramids are displayed in Fig.5. The focused ion beam (FIB) lamellae were cut along the [1100] direction to account for the six-fold symmetry of the InGaN nanopyramids and hence obtain a full description of their morphology. The high-angle annular dark field (HAADF) images Figs.5(a), (b) and (c) illustrate the monocrystallinity and the absence of threading dislocations or resulting V-defects ${ }^{34,35}$ within the InGaN nanopyramids. The fast Fourier transform (FFT) shown in Fig.5(d) confirms their wurtzite atomic arrangement. The energy-dispersive X-ray (EDX) spectral maps shown in Figs.5(e) and (f) highlight the homogeneity of the nanopyramids in both indium and gallium compositions, indicating that there is a single compositional phase in the nanopyramids. Fig.5(a) also shows

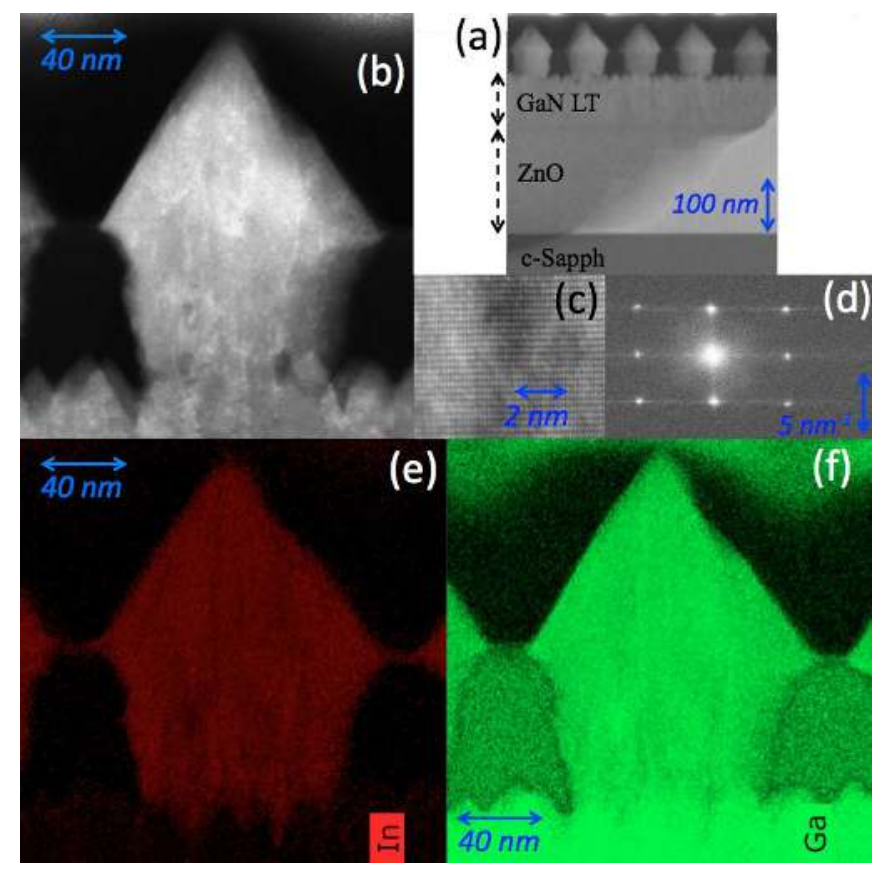

FIG. 5. STEM images of InGaN nanopyramids. (a) HAADF image of 5 consecutive defect-free monocrystalline InGaN nanopyramids grown by NSAG on top of $100 \mathrm{~nm}$ of lowtemperature GaN, which was grown on 200nm-thick $\mathrm{ZnO}$ on c-sapphire. The FIB cut was realized along the [1100] direction. (b) HAADF zoom on one InGaN nanopyramid, illustrating the single-crystal structure and absence of $\mathrm{V}$-pits or threading dislocations which are common to all nanopyramids. (c) A further HAADF zoom of the center of the InGaN nanopyramid in Fig.5(b), revealing wurtzite structure. (d) FFT of Fig.5(c), confirming an hexagonal atomic arrangement in the InGaN. (e) EDX spectral map for the indium emission peak. (f) EDX image for the gallium emission peak.

that the LT 100nm-thick GaN epitaxially-grown on $\mathrm{ZnO}$ has relatively small columnar grains, which would be expected to present many stacking faults. However the poor morphology of the LT GaN layer did not appear to affect the high quality of the InGaN nanopyramids, which were comparable with those already observed for GaN and InGaN grown on GaN-on-sapphire ${ }^{18,19}$ and AlNbuffered silicon ${ }^{20}$. Indeed, at the nanoscale, the quality of InGaN on LT-GaN-covered $\mathrm{ZnO}$ templates is comparably simillar to that of GaN-on-sapphire or AlN-on-Si wafers thanks to our approach where the size of the opening favors formation of one crystal seed to grow regardless of the quality of substrate: as growth proceeds in the openings less than $100 \mathrm{~nm}$-wide diameter, the growth dynamics favor the formation of only one preferential crystal seed in the openings and all the growth in the nanoopening undergoes elastic strain relaxation after reaching critical thickness without generating any strain related degradations, due to the availability of free lateral surfaces; hence we typically have no dislocations, no cracks even if the buffer layer is polycrystalline, of AlN-on- $\mathrm{Si}^{20}$.

In addition, the optical properties of these nanostructures were studied using depth-resolved cathodolumines- 


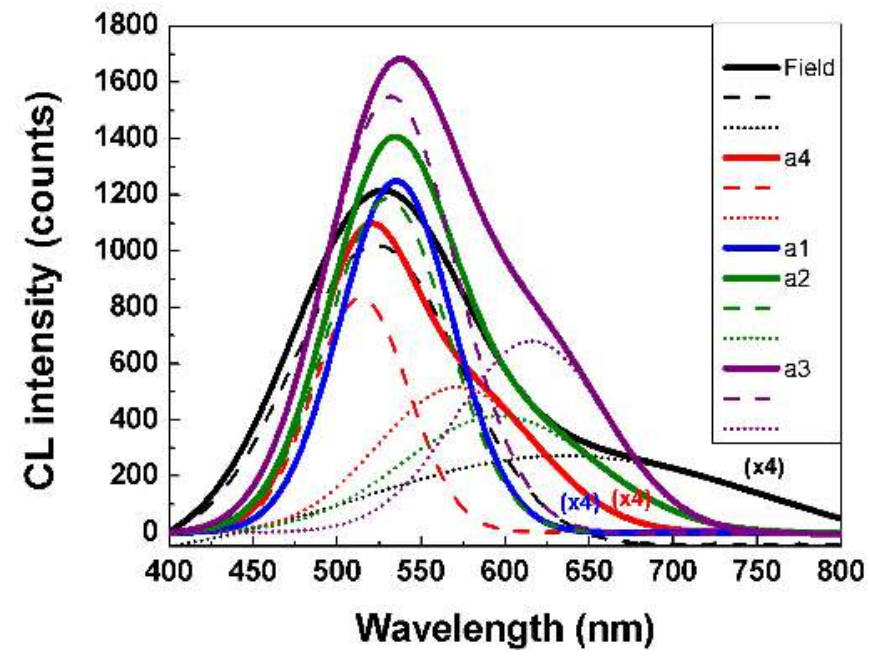

FIG. 6. Cathodoluminescence (CL) measurements at $77 \mathrm{~K}$ on nanopyramids in patterns (a1) to (a4) and the field. All measurements come from one sample, meaning that all the patterned areas and the field experienced the same growth conditions.

cence spectroscopy (CL), see Fig.6. The spectra all show homogeneous main CL emission peaks in the green region of the visible spectrum, with centers between $535 \mathrm{~nm}$ $(2.32 \mathrm{eV})$ and $519 \mathrm{~nm}(2.39 \mathrm{eV})$, respectively corresponding to relaxed high-quality $\mathrm{In}_{.22} \mathrm{Ga}_{.78} \mathrm{~N}$ and $\mathrm{In}_{.20} \mathrm{Ga} .{ }_{78} \mathrm{~N}$ (calculated using Ref. ${ }^{36}$ ).There are red shifts in the emission peaks for arrays (a1), (a2) and (a3), confirming an increase in indium incorporation in these nanostructures compared to the unpatterned area. For masks (a2), (a3) and $(\mathrm{a} 4)$, there is a distinct red-shifted shoulder which is very small, compared to the InGaN in the areas of conventional growth (a.k.a. the field, black curve on Fig.6). This shows that indium incorporation is significantly more homogeneous in the nanostructures than in the field. As a remark on the red-shifted shoulders we found in previous study ${ }^{37}$, in the case of InGaN grown on $\mathrm{AlN} / \mathrm{Si}$ substrate by NSAG, that depending on mask margin size and growth temperature, the relative and overall intensity of the two-peak emission can be controlled. The study suggests that the mask margin role in the color ratio is directly related to the delay of the transition between pseudomorphic and relaxed growth modes because of increased local TMIn concentration due to vapor phase diffusion and increased local free Indium atoms due to surface migration. The increased TMIn concentration has this effect even when it does not enhance growth rate or composition. Comparable studies by different groups have led to similar conclusions ${ }^{38-40}$.

To conclude, NSAG of regular single-crystal InGaN nanopyramid arrays was achieved on GaN-coated $\mathrm{ZnO}$ epitaxial substrates by MOVPE. The relatively poor quality of the low-temperature GaN layer epitaxially grown on $\mathrm{ZnO}$ did not seem to impact the quality of the nanopyramids grown on top it by NSAG. Indeed they were thick (100 nm), indium-rich (up to $22 \%$ ), single crystalline, dislocation-free, uniform, and thus comparable to high-quality InGaN nanostructures grown on GaN (see Refs. ${ }^{18,19}$ ) and AlN/Si (see Ref. ${ }^{20}$ ) templates. LT-GaN can also be $n$-doped with the $\mathrm{ZnO}$ templates with a high flow of silane, and optimized low temperature $\left(800^{\circ} \mathrm{C}\right)$ lateral growth of p-doped (precursor $\mathrm{Cp} 2 \mathrm{Mg}$ ) $\mathrm{GaN}$ on the InGaN nanopyramid exposed semipolar r-plane facets, coupled with the selective etching of the $\mathrm{ZnO}$, has the potential to transfer the optoelectronic PIN structure onto flexible and/or cheaper substrates.

The authors would like to thank the French National Research Agency (ANR), under the NOVAGAINS project (ANR-12-PRGE-0014- 02), the CNRS INCEPT PEPS project, and the ANR project TEMPOS (reference ANR -10- EQPX -50) obtained in the framework of the "Future Investments " program.

${ }^{1}$ Matsuoka T, Okamoto H, Nakao M, Harima H and Kurimoto E 2002 Applied Physics Letters 81 1246-1248

${ }^{2}$ Nakamura S, Pearton S and Fasol G 2000 Springer - The Blue Laser Diode: The Complete Story

${ }^{3}$ Pereira S, Correia M, Pereira E, O'Donnell K, Trager-Cowan C, Sweeney F and Alves E 2001 Physical Review B 64 ISSN 10980121

${ }^{4}$ Rao M, Kim D and Mahajan S 2004 Applied Physics Letters 85 1961-1963 ISSN 0003-6951

${ }^{5}$ Jani O, Ferguson I, Honsberg C and Kurtz S 2007 Applied Physics Letters 91 ISSN 0003-6951

${ }^{6}$ Chen X, Matthews K D, Hao D, Schaff W J and Eastman L F 2008 Physica Status Solidi A 205 1103-1105 ISSN 1862-6300

${ }^{7}$ Farrell R M, Neufeld C J, Cruz S C, Lang J R, Iza M, Keller S, Nakamura S, DenBaars S P, Mishra U K and Speck J S 2011 Applied Physics Letters 98 ISSN 0003-6951

${ }^{8}$ El Gmili Y, Orsal G, Pantzas K, Ahaitouf A, Moudakir T, Gautier S, Patriarche G, Troadec D, Salvestrini J P and Ougazzaden A 2013 Optical Materials Express 3 1111-1118 ISSN 2159-3930

${ }^{9}$ Young N G, Farrell R M, Hu Y L, Terao Y, Iza M, Keller S, DenBaars S P, Nakamura S and Speck J S 2013 Applied Physics Letters 103 ISSN 0003-6951

${ }^{10}$ Gherasoiu I, Yu K M, Reichertz L A, Kao V M, Hawkridge M, Ager J W and Walukiewicz W 2010 Physica Status Solidi B $\mathbf{2 4 7}$ 1747-1749 ISSN 0370-1972

${ }^{11}$ Bhuiyan A G, Mihara A, Esaki T, Sugita K, Hashimoto A, Yamamoto A, Watanabe N, Yokoyama H and Shigekawa N 2012 MOVPE growth of InGaN on $\mathrm{Si}(111)$ substrates with an intermediate range of In content Physica Status Solidi $C$ vol 9 ed Parbrook, PJ and Martin, RW and Halsall, MP pp 670-672

${ }^{12}$ Yamamoto A, Mihara A, Zheng Y and Shigekawa N 2013 Japanese Journal of Applied Physics 52 ISSN 0021-4922

${ }^{13}$ Ho J W, Tan R J, Heuken M, Tay A A and Chua S J 2015 Journal of Crystal Growth $\mathbf{4 2 0} 64-73$

${ }^{14}$ Luryi S and Suhir E 1986 Applied Physics Letters 49 140-142 ISSN 0003-6951

${ }^{15}$ Kuykendall T, Ulrich P, Aloni S and Yang P 2007 Nature Materials 6 951-956 ISSN 1476-1122

${ }^{16}$ Albert S, Bengoechea-Encabo A, Sanchez-Garcia M A, Kong X, Trampert A and Calleja E 2013 Nanotechnology 24 ISSN 09574484

${ }^{17}$ Jindal V, Tripathi N, Tungare M, Paschos O, Haldar P and Shahedipour-Sandvik F 2008 Selective area heteroepitaxy of low dimensional a-plane and c-plane InGaN nanostructures using pulsed MOCVD Physica Status Solidi $C$ vol 5 ed Palacios, T and Jena, D pp 1709-1711

${ }^{18}$ Sundaram S, Puybaret R, El Gmili Y, Li X, Bonanno P L, Pantzas K, Orsal G, Troadec D, Cai Z H, Patriarche G, Voss P L, Salvestrini J P and Ougazzaden A 2014 Journal of Applied Physics 116163105

${ }^{19}$ Sundaram S, Puybaret R, Li X, El Gmili Y, Streque J, Pantzas K, 
Orsal G, Patriarche G, Voss P L, Salvestrini J P and Ougazzaden A 2015 Physica Status Solidi A $\mathbf{2 1 2} 740$

${ }^{20}$ Sundaram S, El Gmili Y, Puybaret R, Li X, Bonanno P L, Pantzas K, Patriarche G, Voss P L, Salvestrini J P and Ougazzaden A 2015 Applied Physics Letters 107 -

${ }^{21}$ Goh W H, Martin J, Ould-Saad S, Gautier S, Sirenko A A, Martinez A, Le Gratiet L, Ramdane A, Maloufi N and Ougazzaden A 2009 Selective growth of GaN nanodots and nanostripes on $6 \mathrm{H}-\mathrm{SiC}$ substrates by metal organic vapor phase epitaxy Physica Status Solidi $C$ vol 6 pp S510-S513

${ }^{22}$ Pearton S, Norton D, Ip K, Heo Y and Steiner T 2005 Progress in Materials Science 50293 - 340

${ }^{23}$ Kawai Y, Ohsuka S, Iwaya M, Kamiyama S, Amano H and Akasaki I 2009 Physica Status Solidi C 6 S486-S489

${ }^{24} \mathrm{Li}$, Nola and Wang, Shen-Jie and Park, Eun-Hyun and Feng, Zhe Chuan and Tsai, Hung-Lin and Yang, Jer-Ren and Ferguson, Ian 2009 Journal of Crystal Growth 311 4628-4631

${ }^{25}$ Rogers D J, Teherani F H, Ougazzaden A, Gautier S, Divay L, Lusson A, Durand O, Wyczisk F, Garry G, Monteiro T, Correira M R, Peres M, Neves A, McGrouther D, Chapman J N and Razeghi M 2007 Applied Physics Letters 91 ISSN 0003-6951

${ }^{26}$ Rogers D J, Hosseini Teherani F, Yasan A, McClintock R P, Mayes K, Darvish S R, Kung P, Razeghi M and Garry G 2005 Proceedings of SPIE $\mathbf{5 7 3 2} 412-416$

${ }^{27}$ Sundaram, S and Li, $\mathrm{X}$ and El Gmili, Y and Bonanno, P L and Puybaret, $\mathrm{R}$ and Pradalier, $\mathrm{C}$ and Pantzas, $\mathrm{K}$ and Patriarche, G and Voss, P L and Salvestrini, J P and Ougazzaden, A 2016 Nanotechnology

${ }^{28}$ Nause J and Nemeth B 2004 The 3rd International Workshop on $\mathrm{ZnO}$ and Related Materials, Sendai, Japan

${ }^{29}$ Li N, Park E H, Huang Y, Wang S, Valencia A, Nemeth B, Nause $\mathrm{J}$ and Ferguson I 2006 Growth of $\mathrm{GaN}$ on $\mathrm{ZnO}$ for solid state lighting applications 6th International Conference on Solid State Lighting, San Diego, CA, Aug 14-17, 2006 (Proceedings of the Society of Photo-Optical Instrumentation Engineers (SPIE) vol
6337) (SPIE) p Z3370

${ }^{30}$ Romano L, Krusor B and Molnar R 1997 Applied Physics Letters 71 2283-2285 ISSN 0003-6951

${ }^{31}$ Strittmatter A, Krost A, Turck V, Strassburg M, Bimberg D, Blasing J, Hempel T, Christen J, Neubauer B, Gerthsen D, Christmann T and Meyer B 1999 Materials Science and Engineering B 59 29-32 ISSN 0921-5107

${ }^{32}$ Gautier S, Sartel C, Ould-Saad S, Martin J, Sirenko A and Ougazzaden A 2007 Journal of Crystal Growth 298 428-432

${ }^{33}$ Ougazzaden A, Rogers D J, Teherani F H, Moudakir T, Gautier S, Aggerstam T, Saad S O, Martin J, Djebbour Z, Durand O, Garry G, Lusson A, McGrouther D and Chapman J N 2008 Journal of Crystal Growth 310 944-947

${ }^{34}$ Heying, $\mathrm{B}$ and $\mathrm{Wu}, \mathrm{XH}$ and Keller, $\mathrm{S}$ and $\mathrm{Li}, \mathrm{Y}$ and Kapolnek, D and Keller, BP and DenBaars, Sp P and Speck, JS 1996 Applied Physics Letters 68 643-645

${ }^{35} \mathrm{Wu}, \mathrm{XH}$ and Elsass, CR and Abare, A and Mack, M and Keller, S and Petroff, PM and DenBaars, SP and Speck, JS and Rosner, SJ 1998 Applied Physics Letters 72 692-694

${ }^{36}$ Orsal G, El Gmili Y, Fressengeas N, Streque J, Djerboub R, Moudakir T, Sundaram S, Ougazzaden A and Salvestrini J P 2014 Optical Materials Express 4 1030-1041 ISSN 2159-3930

${ }^{37}$ Gmili Y E, Bonanno P L, Sundaram S, Li X, Puybaret R, Patriarche G, Pradalier C, Decobert J, Voss P L, Salvestrini J P and Ougazzaden A 2017 Optical Materials Express 7 376-385

${ }^{38}$ Soh, CB and Liu, W and Yong, AM and Chua, SJ and Chow, SY and Tripathy, S and Tan, RJN 2010 Nanoscale Research Letters 5 1788-1794

${ }^{39} \mathrm{Lim}, \mathrm{W}$ and Kum, $\mathrm{H}$ and Choi, YJ and Sim, SH and Yeon, JH and Kim, JS and Seong, HK and Cha, NG and Kim, YI and Park, YS and Yoo, G and Pearton, SJ 2016 Journal of Vacuum Science Technology B $\mathbf{3 4}$

${ }^{40}$ Sekiguchi, $\mathrm{H}$ and Kishino, $\mathrm{K}$ and Kikuchi, A 2010 Applied Physics Letters 96231104 